\title{
A análise de gêneros discursivos na Linguística Forense: um estudo sobre os Golpes do Falso Sequestro
}

\author{
Welton Pereira e Silva ${ }^{a}$ \\ Mônica Santos de Souza Melo ${ }^{b}$
}

\begin{abstract}
Resumo
Os crimes de extorsão chamados de Golpes do Falso Sequestro são uma modalidade criminal que surgiu há poucos anos no Brasil. Como uma nova prática social, atrelado a ela, surgiu também um novo gênero discursivo. No presente artigo, nos propomos a analisar e descrever esse gênero tomando por base a teoria Semiolinguística de Patrick Charaudeau. Nosso corpus de análise foi constituído por quatro gravações de golpes do falso sequestro interceptadas pela polícia civil do Rio de Janeiro e disponibilizadas na modalidade online pela revista Veja. Notamos que as situações comunicativas dos textos que compunham nosso corpus eram orientadas para a finalidade comum de convencer as vítimas a efetuarem o pagamento do falso resgate, já que tanto as visadas discursivas quanto os modos de organização do discurso corroboravam para esse fim. A visada discursiva do fazer-acreditar consiste, nos textos analisados, em fazer com que a vítima acredite nos argumentos dos supostos sequestradores e, através de coerções, ameaças e mesmo instruções, os criminosos procuram fazer com que as vítimas façam o pagamento solicitado (fazer-fazer). Notamos também que o modo argumentativo de organização do discurso é o mais proeminente, sendo auxiliado pelos modos narrativo e descritivo. Tendo, portanto, uma finalidade específica, uma ancoragem social na prática criminal homônima e possuindo, inclusive, identidades próprias dos sujeitos participantes do contrato interacional (sequestrador, sequestrado, vitima-familiar), notamos que os golpes do falso sequestro podem ser considerados como um gênero discursivo próprio.
\end{abstract}

Palavras-chave: Golpes do falso sequestro. Gêneros discursivos. Teoria Semiolinguística.

\footnotetext{
a UFV - Universidade Federal de Viçosa - weltonp.silva@hotmail.com

b UFV - Universidade Federal de Viçosa - monicassmelo@yahoo.com.br
} 


\section{Introdução}

O presente artigo se insere na área da Análise do Discurso Forense. Levando em consideração que a Linguística Forense procura, dentre outros interesses, estudar a linguagem utilizada em contextos legais, iremos analisar as características do gênero "golpe do falso sequestro" sob o arcabouço teórico da teoria Semiolinguística, de Patrick Charaudeau.

Para que nosso objetivo seja atingido, partiremos de alguns postulados da teoria supracitada para fazermos a descrição e a análise do que estamos chamando de gênero golpe do falso sequestro, já que essa atividade comunicativa possui uma finalidade específica e um propósito comunicativo inerente, dentre outras características, que a diferenciam de outras práticas linguageiras.

Na primeira seção, apresentamos a área da Linguística Forense e explicitamos os motivos que nos levaram a introduzir nosso estudo nesta área de pesquisa.

Posteriormente, apresentamos algumas questões relativas à análise e descrição de gêneros discursivos, tomando como ponto de partida os estudos clássicos acerca dos gêneros, passando pelas ideias bakhtinianas e culminando com a proposta de análise de gêneros situacionais apresentada por Charaudeau (2004; 2008).

A terceira seção analisa o corpus de pesquisa que é constituído por quatro gravações de ligações telefônicas de golpes do falso sequestro, selecionadas aleatoriamente a partir de gravações que foram disponibilizadas em áudio, na modalidade online, pela revista Veja. Essas gravações foram por nós transcritas para facilitar a descrição e a análise do corpus. É interessante ressaltar que, dada a natureza complexa do corpus, apenas alguns aspectos, mais pertinentes à nossa pesquisa, serão analisados.

A seção final, por sua vez, traz reflexões e considerações finais a respeito dos resultados da pesquisa.

\section{A Linguística Forense e a análise de gêneros}

A Linguística Forense (LF) é uma área da Linguística Aplicada que tem como finalidade investigar a respeito da linguagem utilizada em âmbito judicial, bem como contribuir 
para a solução de algum crime no qual alguma prova tenha a linguagem como componente. Dessa forma, a fonética forense, área mais consolidada, recebe o apoio de outras áreas linguísticas, como a estilística e a sociolinguística variacionista, por exemplo, para a solução de crimes envolvendo desde a gravação da voz do suspeito até a escrita em bilhetes, mensagens de celular, cartas de suicídio, dentre outros materiais (COULTHARD \& JOHNSON, 2007).

Além do reconhecimento de locutor e da atribuição de autoria a textos apócrifos, a LF também procura analisar a linguagem utilizada em questões legais, tendo como preocupação de pesquisa a prolixidade da linguagem jurídica, a interação em ambiente judicial, a tradução legal e a análise do discurso forense. Dentro dessa última linha, podemos incluir as pesquisas que se debruçam sobre a análise de gêneros discursivos ou textuais característicos do âmbito judicial. Como se sabe, alguns gêneros são próprios da esfera discursiva do Direito, como as petições judiciais, os documentos pessoais (certidão de casamento, nascimento, óbito), os boletins de ocorrência policiais, para citar alguns gêneros que se configuram pela linguagem escrita, bem como outros gêneros cuja existência se dá na conversação, como as audiências de conciliação.

Nesta pesquisa, analisamos os discursos produzidos nas interações criminosos-vítimas em golpes do falso sequestro por entendermos que o discurso criminoso também deva ser analisado no seio da Linguística Forense. De acordo com Olson:

"A Linguística Forense é a aplicação do conhecimento linguístico a um ambiente social particular, nomeadamente o fórum (é daí que provém a palavra forense). Em sentido mais amplo, podemos dizer que a Linguística Forense é a interface entre linguagem, crime e lei, onde lei inclui a aplicação da lei, a matéria jurídica, a legislação, disputas ou procedimentos legais, e até mesmo disputas que só envolvem potencialmente alguma infração da lei ou alguma necessidade de encontrar uma solução legal. Dada a centralidade do uso da linguagem para a vida em geral e, em particular, para a lei, é talvez um pouco surpreendente que a Linguística Forense seja um parente recém-chegado à arena, enquanto outras disciplinas, como a identificação de impressões digitais e análises de pegadas, são muito mais antigas e possuem uma presença bem estabelecida em processos judiciais". (OLSON, s/d, p. 02. Tradução nossa). 
Dessa forma, visto que essa disciplina busca analisar, também, as questões envolvendo a interface entre a linguagem e o crime, o termo Linguística Forense é mais pertinente para abarcar a nossa pesquisa do que o termo Linguística Jurídica, menos abrangente, mas preferido por alguns pesquisadores como, por exemplo, Carapinha (2010). No entanto, mesmo possuindo um sentido não tão globalizante, a autora supracitada define o domínio da Linguística Jurídica afirmando que "ele consiste na aplicação de metodologias e teorias linguísticas a questões de natureza legal e judiciária" (CARAPINHA, 2010, p. 02). Ou seja, mesmo preferindo utilizar-se da nomenclatura Linguística Jurídica, a autora reconhece que essa área interdisciplinar tenta resolver questões relacionadas à natureza legal, da qual o crime faz parte.

Isto posto, explicitamos, a seguir, a nossa afiliação teórica nos domínios da Análise do Discurso.

\section{O estudo sobre os gêneros: da Antiguidade à Semiolinguística.}

Os estudos acerca dos gêneros podem ser remetidos a Aristóteles quando este faz a distinção entre os gêneros da retórica ateniense, nomeadamente o jurídico (que serve para acusar ou defender), o deliberativo (persuadir) e o epidídico (elogiar). Cada um destes relacionado a uma área de atuação dos cidadãos da polis de Atenas, ao menos as áreas consideradas mais importantes. Eram considerados cidadãos atenienses aqueles indivíduos que detinham liberdade. Dessa forma, os gêneros considerados mais importantes para receberem uma denominação foram esses ligados às atividades listadas acima. De acordo com Miller,

“Sem dúvida, os atenienses antigos tinham muitas situações
recorrentes adicionais onde o discurso era usado - na Edu-
cação, por exemplo, ou nas transações comerciais, ou nas
relações diplomáticas, ou nos rituais religiosos - e a tradi-
cional restrição a esses três discursos pode nos dizer mais
sobre Aristóteles do que sobre Atenas" (MILLER, 2009, p. 47).

Também é atribuída a Aristóteles a classificação dos gêneros literários em três grupos: o gênero lírico (que inclui a ode, o hino), o gênero épico (epopéia) e o gênero dramático 
(comédia, tragédia). Essa classificação, mais genérica, acabou por se dividir para abarcar novos gêneros literários que surgiram posteriormente, como o romance e o conto. Na crítica literária atual, podemos encontrar essas classificações que levam em conta certos aspectos relacionados à forma e ao conteúdo das obras produzidas, como a extensão e a escrita (seja em prosa ou em verso). Apesar de taxonômica, a classificação literária se preocupa, também, com a finalidade do gênero para classificá-lo. No entanto, é nas tradições textuais e discursivas de análise do gênero que essas questões passaram a ocupar um lugar central.

No âmbito da análise discursiva, desde Bakhtin os gêneros do discurso são considerados como "tipos relativamente estáveis de enunciado" (2003, p. 262). Essa relatividade sugere que os gêneros não são entidades fixas, mas podem sofrer variações de forma e conteúdo e ainda serem considerados como um mesmo gênero. De acordo com o autor, é através dos gêneros que a linguagem verdadeiramente surge nas práticas sociais, ou seja, se nos comunicamos, se agimos pela língua, o fazemos através dos gêneros do discurso. A partir disso, Bakhtin mostra que cada função social gera um determinado gênero, ou seja, os gêneros surgem, ou se modificam, a partir de (e em consonância com) novas práticas sociais:

“Uma determinada função (científica, técnica, publicística, oficial, cotidiana) e determinadas condições de comunicação discursiva, específicas de cada campo, geram determinados gêneros, isto é, determinados tipos de enunciados estilísticos, temáticos e composicionais relativamente estáveis". (BAKHTIN, 2003, p. 266)

Considerando, então, a ligação essencial dos gêneros com os contextos sociais, Swales (2009) nos lembra que a partir da década de oitenta passou-se a perceber uma preocupação em se classificar os gêneros a partir de seu propósito comunicativo, ou seja, a finalidade de utilização de um gênero em uma determinada prática social. Swalles, no entanto, chama a atenção para o fato de que o propósito não deve ser, necessariamente, considerado como uma maneira infalível de se classificar um gênero, afinal, o propósito está atrelado a toda a situação contextual que circunda a produção e utilização de um determinado gênero. Dessa forma, o autor sugere que o conceito de 
propósito comunicativo deva ser utilizado para a classificação genérica, mas que este não deve ser considerado o único aparato de análise. Observa-se, portanto, uma preocupação com o contexto social que envolve os eventos comunicativos para se fazerem as classificações genéricas, o que encontramos, de forma mais acentuada, nas tradições de análise discursiva.

Tomando por ponto de partida a definição basilar dos gêneros do discurso, de Bakhtin, e estando atentos para essas questões que envolvem a análise de gêneros de acordo com o contexto, estamos, no presente artigo, analisando o discurso dos golpes do falso sequestro como um gênero discursivo sob a perspectiva da teoria Semiolinguística de Patrick Charaudeau. De acordo com esse analista do discurso, todo ato de linguagem se realiza em uma situação de comunicação. Segundo Charaudeau (2010, p. s/p):

\begin{abstract}
"A 'situação de comunicação' é o lugar onde se instituem as instruções que determinam a expectativa da troca, estas instruções provenientes ao mesmo tempo da 'identidade' dos parceiros e do lugar que eles ocupam na troca, da 'finalidade' que os religa em termos de finalidade, do 'propósito' que pode ser convocado e das 'circunstâncias materiais nas quais a troca se realiza'. Quando um conjunto de situações partilha as mesmas características, mesmo se algumas outras são diferentes, isso quer dizer que elas se encontram em um mesmo domínio de comunicação".
\end{abstract}

Para o autor, durante uma troca linguageira é estipulado um contrato de comunicação entre os participantes da interação. Esse contrato ditará as regras de como os participantes devem proceder diante de determinadas situações discursivas, o que, segundo ele, irá configurar os diferentes gêneros discursivos. Estes serão fruto da situação de comunicação, das identidades dos parceiros do ato comunicacional, da situação na qual esse ato se realiza e da finalidade desse ato. Em outras palavras, o que os participantes fazem no ato linguageiro, o contexto e a finalidade desse ato configuram as situações de comunicação. Essas situações de comunicação configuram os gêneros do discurso de acordo com a teoria semiolinguística e é por isso que Charaudeau denomina os gêneros discursivos como gêneros situacionais, já que estes são dependentes das situações discursivas nas quais se encontram. 
Charaudeau (2004) propõe que a análise de gêneros deve ser pautada sobre quatro aspectos que devem ser inter-relacionados, a saber: a ancoragem social do discurso, que liga um gênero a uma determinada prática social; a sua natureza comunicacional; as atividades linguageiras e as características formais dos textos produzidos. Para o autor, uma abordagem completa do assunto leva em conta todos esses parâmetros. A questão da finalidade, tida como o principal diversificador dos gêneros, passa a ser analisada a partir das visadas discursivas, que podem ser entendidas como "maneiras de dizer", e assim, "cada situação de comunicação seleciona, para definir sua finalidade, uma ou várias visadas dentre as quais, geralmente, uma (às vezes duas) é dominante" (CHARAUDEAU, 2004, p. 25). Além disso, o autor também diz que as finalidades discursivas do ato de comunicação são ordenadas por determinadas categorias de língua que podem ser agrupadas em quatro modos de organização do discurso: o enunciativo, descritivo, narrativo e argumentativo. (CHARAUDEAU, 2004; 2008).

Nossa análise se pautará, portanto, sobre a(s) finalidade(s) do gênero golpe do falso sequestro, partindo da relação entre as identidades dos parceiros da troca, o propósito comunicativo, as circunstâncias materiais nas quais se localizam as situações de comunicação que compõem o corpus e os modos de organização predominantes nos textos analisados.

\section{O gênero Golpe do Falso Sequestro: descrição e análise}

Os golpes do falso sequestro, como passaram a ser conhecidos, os disque-sequestro, começaram a vigorar no início dos anos dois mil, principalmente na cidade do Rio de Janeiro e arredores. Nessas tentativas de extorsão, os criminosos fazem ligações, normalmente de dentro de presídios, para uma vítima aleatória e, através de ameaças, tentam convencer a vítima a efetuar o pagamento do falso resgate. Os pagamentos variam desde recargas de celulares até quantias menores, que podem, sob o ponto de vista do criminoso, ser conseguidas rapidamente. Por esse motivo, o resgate não ultrapassa o valor de dez mil reais (RODRIGUES, 2007), sendo o valor médio de quatro mil reais (LINHARES, 2007). Além disso, é interessante ressaltar, também, que cerca de $20 \%$ das vítimas efetuam o pagamento do falso resgate, o que vem a consumar essa prática que con- 
siste em um tipo de crime de extorsão, definidos por Santos (2001, p. 96) como um "crime de constrangimento a (sic) pessoa, através da violência ou ameaça, com a intenção de obter para si ou para outrem vantagem financeira ou econômica".

Para a presente pesquisa, utilizamos um corpus constituído por quatro gravações telefônicas de tentativas de extorsão interceptadas pela Polícia Civil do Rio de Janeiro e disponibilizadas, em áudio, pela revista Veja na modalidade online como parte de uma reportagem que tinha como tema os golpes do falso sequestro. A partir das gravações, fizemos as transcrições dos textos de forma a facilitar a nossa análise.

Nos golpes do falso sequestro, o propósito diz respeito a uma simulação, por parte do criminoso, de um sequestro de algum familiar da pessoa que atendeu o telefonema. Através de chantagens e ameaças, o falante tenta fazer com que a vítima efetue o pagamento do falso resgate. Como verificamos em estudo anterior (SILVA \& MELO, 2013), durante o processo interacional, os criminosos fazem uso de alguns argumentos patêmicos, que buscam respaldo nas emoções que a vítima nutre pelo seu familiar, para convencê-la a efetuar o pagamento do resgate. Esses argumentos envolvem, normalmente, a ameaça à vida do suposto sequestrado através, principalmente, da morte pelo fogo, a descrição da cena na qual se encontra o familiar e a atribuição de culpa à vítima pela morte do seu ente querido. Essas questões serão retomadas em nossa análise.

As circunstâncias, que se referem às condições materiais da comunicação, se restringem a uma comunicação telefônica, instaurada por iniciativa do(s) criminoso(s), que liga(m), normalmente no período noturno, para uma vítima escolhida, em geral, aleatoriamente.

A finalidade principal da situação de comunicação aqui analisada é a de extorquir as vítimas. Para isso, os autores recorrem à visada de fazer-crer, procurando levar a pessoa que atendeu o telefonema a pensar que seu ente querido está mesmo em posse dos pseudossequestradores. Adotam também uma visada de informação, relatando uma situação simulada que representaria a maneira como a pessoa teria sido sequestrada e/ou ainda detalhes sobre o seu estado. Através dessas descrições, os delinquentes tentam criar uma espécie de efeito de real, através do qual poderiam convencer a vítima da ve- 
racidade de suas afirmações, levando-a, por consequência, a pagar o resgate exigido. Trata-se, aqui, da visada de incitação, pela qual o comunicante procura fazer o outro acreditar que deve praticar a ação para seu próprio bem ou para beneficiar um ente querido. Como afirma Charaudeau (2004), na visada de incitação:

"Eu quer "mandar fazer" (faire faire), mas, não estando em posição de autoridade, (...) não pode senão incitar a fazer; ele deve, então, "fazer acreditar" (por persuasão ou sedução) ao $t u$ que ele será o beneficiário de seu próprio ato; $t u$ está, então, em posição de "dever acreditar" que, se ele age, é para o seu bem" (CHARAUDEAU, 2004, p. 23).

No caso dos textos aqui analisados, o Eu que se configura no sujeito enunciador do sequestrador não está em posição de exigir o pagamento por si só, por isso, ele tenta fazer com que o Tu, o sujeito destinatário, acredite em seus argumentos e creia que sua ação será boa para ele próprio e para seu ente querido supostamente sequestrado. Na Teoria Semiolinguística o sujeito enunciador seria aquele que produz o seu discurso tendo em mente um sujeito destinatário, para quem o enunciado será dirigido.

Além disso, para Charaudeau (2008), existem dois espaços distintos na encenação discursiva: um espaço externo, o fazer do ato de linguagem, o contexto de produção do discurso, e um espaço interno, ou o próprio ato discursivo, o dizer. Portanto, vemos duas instâncias produtoras do discurso e duas receptoras, sendo que o Eu enunciador (EUe) e o Tu destinatário (TUd) se concretizam no Eu comunicante (EUc) e no Tu interpretante (TUi), respectivamente. Dessa forma, a Semiolinguística entende que na encenação discursiva agem diferentes sujeitos: o EUc e o TUi constituindo os seres empíricos, sociais e psicológicos entendidos como os parceiros do ato de linguagem e o EUe e o TUd que, por sua vez, são seres de fala que existem apenas na e pela enunciação.

Por fim, percebemos também na situação de comunicação aqui analisada a visada de instrução: o EUe se encontra numa posição de autoridade pelo fato de deter um saber-fazer e o TUd está numa posição de dever-saber-fazer. No gênero analisado, tal visada se manifesta quando os criminosos dizem para as 
vítimas como elas devem agir para que nada aconteça com o suposto sequestrado.

Quanto às identidades construídas, o contrato comunicativo instaurado atribui as identidades principais de sequestrador e de vítima às pessoas envolvidas. $\mathrm{O} E u$ enunciador, primeiramente, constrói para si a identidade de saber, sendo alguém que detém as informações sobre o suposto sequestrado e que pode, também, solucionar tal situação. Verifica-se que, na maior parte dos casos, o Eu enunciador se apresenta como o próprio sequestrador. Cria-se uma imagem ambígua, pois, ao mesmo tempo em que se propõe uma imagem de algoz, o sujeito falante pode se mostrar como o benfeitor, sendo capaz de "devolver" a liberdade ao sequestrado. Também ocorrem situações em que há mais de um criminoso envolvido. Nesses casos, um dos criminosos assume a identidade do suposto sequestrado. O Tu destinatário corresponde, também, a uma figura ambígua, pois é concebido como uma vítima, por ser alguém que sofrerá por ter um ente querido mantido em cativeiro, mas também é concebido como agente, alguém que será capaz de qualquer coisa para libertar a vítima. Quando o Tu interpretante, parceiro real que compõe a instância de recepção, toma a vez de sujeito enunciador, a identidade de vítima é a que prevalece.

As restrições situacionais descritas acima conduzem a um conjunto de restrições discursivas do gênero em questão. As restrições discursivas referem-se a "um conjunto de comportamentos discursivos possíveis entre os quais o sujeito escolhe aqueles que são suscetíveis de satisfazer às condições dos dados externos." (CHARAUDEAU, 2004, p. 27). A partir dos dados que analisamos, podemos dizer que a finalidade de extorquir as vítimas e as visadas a ela relacionadas conduzem ao predomínio, por parte do comunicante, do emprego da modalidade alocutiva, que se caracteriza pelo fato de o sujeito falante enunciar sua posição em relação ao interlocutor, implicando-o e impondo a ele um comportamento. Trata-se, portanto, de uma relação de influência, caracterizada pelo uso da injunção, que estabelece para o outro uma ação que deve ser executada, atribuindo a si um estatuto de poder. É o que se pode constatar através do exemplo seguinte:

(1) Então fica na linha, numa boa, sem chamar o seu marido e sem envolver outra pessoa. (texto II, em anexo) 
Tais enunciados são quase sempre seguidos de ameaça, modalidade que se caracteriza pela intenção do falante de prevenir o interlocutor sobre os riscos decorrentes da desobediência às condições impostas, como se verifica em:

(2) A senhora está disposta a resolver, ou a gente vai ter que tirar a vida dela? (texto IV)

(3) Se a senhora tentar chamar seu marido, ou tentar desligar o telefone, a gente vai tacar gasolina e tocar fogo nela, tá me entendendo? (texto II)

Por parte do sujeito interpretante, verifica-se também o predomínio da modalidade alocutiva, especificamente, a interrogação, a partir da qual a vítima procura obter detalhes sobre a situação e sobre o estado do parente supostamente sequestrado. É o que observamos em:

(4) Onde você vai me entregar ele? (texto III)

Para obter a finalidade a que se propõe, o sujeito falante adota procedimentos de ordem argumentativa, que se baseiam na presença de um sujeito que elabora uma proposta direcionada a outro sujeito, que constitui o alvo da argumentação. Tal argumentação, nos dados estudados, se baseia fortemente no procedimento de dedução condicional (se... então), exemplificado na passagem seguinte:

(5) Se a senhora não quiser negociar, eu vou desligar o telefone e matar a sua filha! (texto II)

Tal procedimento refere-se às condições impostas pelo falso sequestrador para que a situação chegue a um desfecho positivo.

Também recorre-se à descrição e à descrição narrativa, procedimentos em que se descreve algo, alguém ou algum fato para reforçar ou produzir uma prova. É o que se verifica em:

(6) Ela foi vítima de um assalto, trouxemos ela pro interior de uma favela. (texto IV)

(7) Ela foi vítima de um assalto e trazida para o interior de uma favela. Ela que implorou pela própria vida pedindo que a gente ligasse pra senhora, que estaria capacitada pra negociar e soltar ela com vida. (texto IV) 
Tais descrições podem sinalizar uma intenção de criar um efeito de realidade, através do uso de alguns índices que levam a construir uma visão objetiva do mundo, dando a ilusão de que esse universo criado é verdadeiro. Sendo assim, tais descrições possuem um importante valor argumentativo nas situações analisadas, pois levam a vítima a acreditar que o sequestro é real.

A seguir, o quadro 1 apresenta uma relação das principais visadas e dos principais procedimentos encontrados nos quatro textos que compõem o nosso corpus:

Quadro 1 - Visadas e procedimentos.

\begin{tabular}{|c|c|c|c|c|}
\hline Textos & Visadas & Exemplos & Procedimentos & Exemplos \\
\hline Texto I: & Fazer-acreditar & $\begin{array}{l}\text { “Olha só. Ela foi } \\
\text { vítima de um assalto. } \\
\text { Trouxemos ela aqui } \\
\text { pro interior de uma } \\
\text { favela e tamo ligando } \\
\text { pra poder resolver e } \\
\text { negociar pela vida } \\
\text { dela de uma melhor } \\
\text { maneira possível." } \\
\\
\text { "Peço que a senhora } \\
\text { mantenha a calma. } \\
\text { Não fique nervosa, } \\
\text { não envolva qualquer } \\
\text { outro tipo de pessoa } \\
\text { pra não ter que ter } \\
\text { agravante na vida da } \\
\text { sua filha, entendeu?" }\end{array}$ & Descrição narrativa & $\begin{array}{l}\text { "Já mandei tirar ela } \\
\text { daqui. Se a senhora não } \\
\text { quiser negociar, eu vou } \\
\text { desligar o telefone e } \\
\text { matar a sua filha!" } \\
\\
\text { "Ela foi vítima de um } \\
\text { assalto, trouxemos ela } \\
\text { pro interior de uma } \\
\text { favela." } \\
\\
\text { "Peço que mantenha } \\
\text { a calma, não envolva } \\
\text { qualquer tipo de pessoa } \\
\text { pra não ter nenhum } \\
\text { agravante na vida da } \\
\text { sua filha." }\end{array}$ \\
\hline Texto II: & Fazer-acreditar & $\begin{array}{l}\text { "Ela está dentro de um } \\
\text { cativeiro, amarrada e } \\
\text { amordaçada, chorando } \\
\text { muito." } \\
\text { "então fica na linha, } \\
\text { numa boa, sem } \\
\text { chamar o seu marido } \\
\text { e sem envolver outra } \\
\text { pessoa." }\end{array}$ & Dedução condicional & $\begin{array}{l}\text { "Se a senhora tentar } \\
\text { chamar o seu marido, } \\
\text { ou desligar o telefone, a } \\
\text { gente vai tocar fogo na } \\
\text { sua filha viva! É isso } \\
\text { que a senhora quer?" } \\
\\
\text { "A sua filha na verdade } \\
\text { não foi acidentada, } \\
\text { ela tá com a gente, } \\
\text { ela foi vítima de um } \\
\text { sequestro." }\end{array}$ \\
\hline
\end{tabular}




\begin{tabular}{|c|c|c|c|c|}
\hline Texto III: & $\begin{array}{l}\text { Fazer-acreditar } \\
\text { Fazer-fazer }\end{array}$ & $\begin{array}{l}\text { "Você vai ter o seu } \\
\text { filho com vida, mas se } \\
\text { fizer o que eu mandar, } \\
\text { entendeu?" } \\
\text { "Mantenha a } \\
\text { tranquilidade! Eu vou } \\
\text { devolver com vida." }\end{array}$ & $\begin{array}{l}\text { Dedução condicional } \\
\text { Descrição narrativa } \\
\text { Descrição }\end{array}$ & $\begin{array}{l}\text { "Se desligar ou envolver } \\
\text { outra pessoa, eu taco } \\
\text { fogo no corpo dele!" } \\
\text { "Eu não posso falar } \\
\text { quem está falando. } \\
\text { Houve pânico, correria, } \\
\text { a polícia perseguiu a } \\
\text { gente e esse rapaz veio } \\
\text { baleado de raspão na } \\
\text { perna." } \\
\text { "é homem de palavra } \\
\text { com quem a senhora está } \\
\text { falando!" }\end{array}$ \\
\hline Texto IV: & Fazer-acreditar & $\begin{array}{l}\text { "A senhora fica calma. } \\
\text { Ela foi vítima de um } \\
\text { assalto e trazida para o } \\
\text { interior de uma favela. } \\
\text { Ela que implorou pela } \\
\text { própria vida pedindo } \\
\text { que a gente ligasse } \\
\text { pra senhora, que } \\
\text { estaria capacitada pra } \\
\text { negociar e soltar ela } \\
\text { com vida." } \\
\\
\text { "Então ouve. A } \\
\text { senhora vai me } \\
\text { responder todas as } \\
\text { minhas perguntas, só } \\
\text { vai dizer a verdade, } \\
\text { pra gente não fazer } \\
\text { nenhum mal a ela." }\end{array}$ & Narração & $\begin{array}{l}\text { "Nós estamos querendo } \\
\text { uma quantia em } \\
\text { dinheiro pra libertar a } \\
\text { filha da senhora aqui } \\
\text { desse cativeiro. A } \\
\text { senhora está disposta a } \\
\text { pagar?" } \\
\\
\text { "Ela foi vítima de um } \\
\text { assalto e trazida para o } \\
\text { interior de uma favela. } \\
\text { Ela que implorou pela } \\
\text { própria vida pedindo } \\
\text { que a gente ligasse pra } \\
\text { senhora, que estaria } \\
\text { capacitada pra negociar } \\
\text { e soltar ela com vida." } \\
\\
\text { "A senhora vai me } \\
\text { responder todas as } \\
\text { minhas perguntas, só } \\
\text { vai dizer a verdade, pra } \\
\text { gente não fazer nenhum } \\
\text { mal a ela. A nossa } \\
\text { intenção não é essa, a } \\
\text { senhora já percebeu." }\end{array}$ \\
\hline
\end{tabular}

Fonte dos dados: <http://veja.abril.com.br/idade/exclusivo/210207/audios_sequestros.html> 
O propósito desse tipo de comunicação é responsável pela adoção de uma organização temática mais ou menos fixa, que se define pela exposição da situação, com a descrição do sequestro, a negociação de pagamento de um resgate e a ameaça, caso a imposição não seja atendida.

Sendo assim, os aspectos formais desse gênero se revelam, como já postulara Bakhtin, relativamente estáveis, pois podemos perceber que um determinado "script" é seguido durante o percurso do processo interacional:

- A abordagem: nesse primeiro momento, os criminosos interpretam o suposto sequestrado ou alguma outra pessoa para tentar retirar algumas informações básicas da vítima, como, por exemplo, o nome de algum parente próximo. Nessa primeira fase, o modo de organização narrativo se mostra mais proeminente, com os criminosos narrando como foi feita a captura do suposto sequestrado.

- A revelação do sequestro: assim que conseguem algum nome ou outra informação, o primeiro criminoso passa o telefone a outro que anuncia o sequestro. Outra variação é que o próprio delinquente que se passava por outra pessoa anuncia que, na verdade, o parente da vítima está sob sua custódia. A partir daí, os criminosos passam a descrever a situação na qual se encontraria o suposto sequestrado e passam a fazer ameaças e chantagens.

- A negociação: posteriormente, dá-se início a uma série de negociações. Essa fase crítica consiste na utilização de argumentos por parte dos criminosos e contra-argumentos por parte das vítimas. Os delinquentes também fazem uso de coerções e ameaças para tentar fazer com que a vítima não envolva outras pessoas na interação. A utilização de argumentos patêmicos acontece, principalmente, nessa fase. Esses argumentos, conforme notamos em pesquisa anterior, são os mais utilizados na interação, dada sua natureza.

- O desfecho: por fim, após a negociação, a vítima já terá dito se está apta e disposta a efetuar o pagamento do (falso) resgate e, após os últimos acertos, a ligação é 
encerrada. Devemos chamar a atenção, contudo, para o fato de que os textos que constituem nosso corpus não possuem o final propriamente dito. Acreditamos que isso se deve ao fato de dados pessoais, como números telefônicos e contas bancárias, serem explicitados.

De acordo com nossa análise, percebemos que podemos configurar os golpes do falso sequestro como gêneros situacionais, na medida em que são regidos por restrições próprias, ligadas à finalidade da situação comunicativa, à identidade dos sujeitos e à ancoragem social, que os diferem de outros textos produzidos em outras práticas sociais.

\section{Considerações finais}

Os gêneros consistem nos modos regulares e, como dizia Bakhtin, relativamente estáveis através dos quais agimos em sociedade pela linguagem. Devido ao seu espaço, desde a Antiga Grécia os pensadores têm tentado catalogar e descrever os diferentes tipos de gêneros. Em nosso artigo, analisamos e procuramos descrever o gênero golpe do falso sequestro a partir da finalidade de suas situações comunicativas, das identidades dos sujeitos participantes da interação, do propósito comunicativo, da ancoragem social e das questões formais pertencentes a esse gênero situacional. A teoria Semiolinguística de Patrick Charaudeau orientou nossa pesquisa. Notamos que as visadas de fazer-acreditar e fazer-fazer orientam a finalidade dessas práticas linguísticas na medida em que os criminosos (Eu enunciador) procuram convencer as vítimas (Tu destinatário) de que seus entes queridos estão sob seu poder. Os procedimentos ligados ao modo argumentativo reforçam o poder de persuasão do falante, na medida em que a descrição da situação na qual se encontra o suposto sequestrado, bem como a narrativa do episódio do sequestro, fazem com que a credibilidade dos argumentos aumente.

Além disso, consideramos que nossa análise está incluída, também, na área multidisciplinar da Linguística Forense na medida em que nosso objeto de análise consiste em trechos de gravações de tentativas de crimes de extorsão. É interessante ressaltar que estamos nos referindo aos textos como "tentati- 
vas", pois não temos acesso ao desfecho das gravações, o que nos impossibilita saber se as vítimas efetuaram, ou não, o pagamento e consumaram o crime.

\section{REFERÊNCIAS BIBLIOGRÁFICAS}

BAKHTIN, Mikhail. Estética da Criação Verbal. $4^{\mathrm{a}}$ ed. São Paulo: Martins Fontes, 2003.

CARAPINHA, Conceição. A linguagem no 'banco dos réus' - alguns aspectos da Linguística Jurídica. Coimbra: Ciclo de seminários do Celga, 2010.

CELANI, Maria Antonieta Alba. Afinal o que é linguística aplicada? In: PASCHOAL, Maria Sofia Zanoto \& CELANI, Maria Antonieta Alba (Org). Linguística Aplicada: da aplicação de linguística à linguística transdisciplinar. São Paulo: Educ, 1992, p. 15-23.

CHARAUDEAU, Patrick. Linguagem e discurso: modos de organização. Editora Contexto, São Paulo: 2008. Uma problemática comunicacional dos gêneros discursivos. In Revista Signos, vol. 43. PUC, Valparaíso: 2010. Visadas discursivas, gêneros situacionais e construção textual. In: Ida Lucia Machado e Renato de Mello. Gêneros: reflexões em análise do discurso. Belo Horizonte, Nad/ Fale - UFMG: 2004.

COULTHARD, Malcolm; JOHNSON, Alison. An Introduction to Forensic Linguistics: Language in Evidence. New York: Routledge, 2007.

LINHARES, Juliana. Terror pelo telefone. Revista Veja, edição 1996. Editora Abril. 2007. Disponível em <http://veja.abril.com. br/210207/p_038.shtml\#trechos>. Acesso em: 29 mai 2014.

MILLER, Carolyn. Estudos sobre gênero textual, agência e tecnologia. Recife: Ed. Universitária da UFPE, 2009.

OLSON, John. What is Forensic Linguistics? Disponível em: <thetext.co.uk/docs/what_is.doc>. Acesso em 25 mai. 2014.

RODRIGUES, Guilherme Eugênio. Considerações acerca das extorsões realizadas por via telefônica através da simulação de um sequestro. ADPESP - Associação dos Delegados de Polícia 
do Estado de São Paulo, 2007. Disponível em <http://adpesp. org.br/artigos_exibe.php?id=39>. Acesso em: 29 mai. 2014.

SANTOS, Washington dos. Dicionário Jurídico Brasileiro. Del Rey, Belo Horizonte: 2001.

SILVA, Welton Pereira e; MELO, Mônica Santos de Souza. As estratégias argumentativas em crimes de extorsão: uma análise de discursos patêmicos em golpes do falso sequestro. Diálogo das Letras, Pau dos Ferros, v. 02, n. 01, p. 374 - 396, jan./jun. 2013. SWALES, John. When there is no perfect text: Approaches to the EAP practitioner's dilemma. Journal of English for Academic Purposes, v. 08, p. 5-13. 


\section{Abstract \\ Analysis of discursive genres in Forensic Linguistics: a study about Fake Kidnapping Scams}

Crimes of extortion called "Fake Kidnapping Scams" are a criminal modality that emerged few years ago in Brazil. As a new social practice, linked to it also emerged a new discursive genre. In this paper, we proposed to analyze and to describe this genre, based upon the Patrick Charaudeau's Semiolinguistic Theory. Our analysis corpus was constituted by four recordings of "Fake Kidnapping Scams" intercepted by Rio de Janeiro's Civil Police and provided through the online modality by Veja magazine. We realized that the communicative situations of the texts that composed our corpus were oriented to the common purpose of convincing victims to make the payment of the fake rescue, since the discursive target and the modes of discursive organization as well corroborated for this purpose. The discursive target make believe consists, in the analyzed texts, to make the victims believe in the supposed kidnappers' arguments and, through coercion, threats and even instructions, criminals seek to make the victims make the payment requested. We also realized that the argumentative mode of discursive organization is the most prominent, being aided by the narrative and descriptive modes. Having, therefore, a specific finality, a social base in the homonymous criminal practice and having, also, own identities of the participating subjects of the interactional contract (kidnapper, kidnapped, victim-relative), we realized that the Fake Kidnapping Scams might be considered as an own discursive genre.

Keywords: Fake Kidnapping Scams. Discursive genres. Semiolinguistic Theory. 